\title{
Isomerisation of $\alpha$-pinene over Beta zeolites synthesised by different methods
}

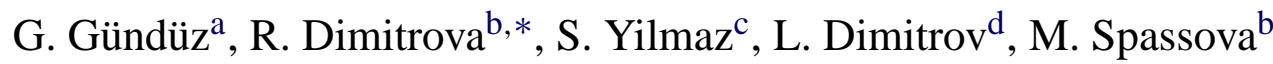 \\ a Department of Chemical Engineering, Ege University, Bornova, Izmir, Turkey \\ ${ }^{\mathrm{b}}$ Institute of Organic Chemistry, Bulgarian Academy of Sciences, 1113 Sofia, Bulgaria \\ ${ }^{\mathrm{c}}$ Department of Chemical Engineering, Izmir Institute of Technology, Izmir, Turkey \\ d Centro de Ciências Exatas e de Tecnologia, Universidade Federal de São Carlos, São Carlos, Brazil
}

Received 1 June 2004; received in revised form 16 September 2004; accepted 18 September 2004

Available online 22 October 2004

\begin{abstract}
Liquid-phase $\alpha$-pinene isomerisation at $100{ }^{\circ} \mathrm{C}$ in a batch reactor is studied over Beta zeolites synthesised by different methods. It is confirmed that $\alpha$-pinene forms a carbenium ion in an acidic environment, which rearranges without capture by nucleophiles, to form mainly hydrocarbons as camphene, terpinenes, terpinolenes and heavy products. The microporous Beta samples show low activity despite the high acidity most probably because of the hindered intermediate formation. The nature of the enhanced activity of Beta mesopores samples is suggested to be a result from the high accessibility of the acidic sites.
\end{abstract}

(C) 2004 Elsevier B.V. All rights reserved.

Keywords: Beta zeolite; Mesopores; Isomerisation; $\alpha$-Pinene

\section{Introduction}

Two important factors are found to contribute mostly to the activity and selectivity of zeolites, used as catalysts for bulky organic molecules - its acidity and textural characteristics. The former factor is related to the type of the existing acidic sites and reflects the ability for a formation of transition state. The second factor depends on the framework topology, in particular the size of the pores. The latter is the reason why only certain molecules enter the channels and why only certain intermediates are formed. Compared to other zeolite structures, Beta zeolite has a high density of stacking defects and accordingly a lot of partially coordinated aluminium that influences the Brönsted acidity [1,2]. The stacking faults do not affect the micropore volume of Beta zeolites, but do influence the easy creation of a secondary porous network that facilitates the reagents and products transport and influences

\footnotetext{
* Corresponding author. Tel.: +359 2 9606111; fax: +359 28700225 .

E-mail address: zeolab@orgchm.bas.bg (R. Dimitrova).
}

the catalytic properties $[3,4]$. The intrinsic characteristics of Beta zeolites could be significantly changed using different methods of synthesis or samples thermal pre-treatment [5]. Recently, the formation of mesopores in different zeolites has reported for zeolites such as Y [6,7], mordenite [8-11], ZSM-5 [12-14].

The isomerisation of $\alpha$-pinene to camphene, used in camphor synthesis, is an intensively studied reaction in the presence of acid-base catalysts $[15,16]$. The protonation of $\alpha$-pinene double bond generates intermediate tertiary carbenium ion that rearrange to a variety of isomers. It is found that if the reaction is run with diluted sulphuric acid a mixture of $p$-menthadienes and little camphene results [17]. In the presence of solid catalysts as: clays $[18,19]$, natural zeolite [20-22], faujasite [23], mid-pore zeolites USY [24], zeolites X and Y [25-27] and a series of highly crystalline silica aluminophosphates having an AFI topology [28], both camphene and limonene are obtained with yield of $68 \%$. It was found that limonene further transforms into other monocyclic products (terpinolenes, terpinenes and 
$p$-cymene), or dimeric and polymeric products. The effects of catalysts type, acidity, the number of framework and non-framework aluminium are investigated on the products distribution. In view of the differences in the conclusions reported on the catalytic behavior of zeolites in liquid-phase isomerisation of $\alpha$-pinene, the main objective of this work has been to follow the influence of parameters as the textural and structural properties of Beta zeolites and its acidity for this reaction. On the basis of the catalytic results, an attempt is done to clear the role of the active sites for the selectivity of $\alpha$-pinene conversion to camphenic compounds.

\section{Experimental}

\subsection{Catalysts}

Beta zeolites with modules $\left(\mathrm{SiO}_{2} / \mathrm{Al}_{2} \mathrm{O}_{3}\right)$ of 20,55 and 66 are investigated. Samples denoted as Beta(20) and Beta(55) are synthesised by hydrothermal crystallisation of the appropriate gels. Beta(66) is obtained according to the steam-assisted crystallisation method [29]. Beta zeolites with mesopores, $m \operatorname{Beta}(66-48)$ and $m \operatorname{Beta}(66-113)$ (the second number in the brackets stands for the time of mesostructuring) are studied as well. A detailed information about catalysts preparation is given in Ref. [5]. Nitrogen physisorption measurements are performed at $77 \mathrm{~K}$ in a static volumetric apparatus (Coulter Omnisorp $100 \mathrm{CX}$ ) up to $P / P_{0} \sim 0.95$. The surface areas and the pore volumes of the samples are obtained from the adsorption isotherms. Langmuir, BET, Dubinin-Astakhov (D-A) and $t$-plot equations are used for the evaluation of the micro- and mesostructural parameters. The limiting micropore volume $\left(W_{0}\right)$ and the value of the exponential constant $(n)$ in the D-A equation are estimated. The $n$ value is related to samples pores heterogeneity. It has been proved that for samples with apparent micropore size, the heterogeneity increases with a decrease of the $n$ value [31]. The monolayer surface area and the half-width of pores are calculated by using Langmuir and Dubinin-Astakhov (D-A) methods [32]. The micropore volumes $\left(V_{\text {micro }}\right)$ and the external surface areas $\left(A_{\text {ext }}\right)$ are calculated from the $t$-plot equation. Samples acidity is checked by temperature-programmed desorption of ammonia (TPDA) and FTIR spectra of adsorbed pyridine [5]. Samples characteristics are systemised in Table 1.

\subsection{Catalytic test}

The isomerisation of $\alpha$-pinene is carried out at atmospheric pressure under nitrogen flow in a glass reactor with a reflux condenser, an efficient stirrer and a temperature controller. In a typical run, $0.5 \mathrm{~g}$ of catalyst and $25 \mathrm{ml}$ of $\alpha$-pinene (Acros) are charged in the reactor. The reaction is carried out at constant temperature of $100^{\circ} \mathrm{C}$ for $3 \mathrm{~h}$. Experiments have been carried out with fresh catalyst, reused catalysts (samples washed by solvent without calcination) and regenerated catalysts (samples calcined at $550^{\circ} \mathrm{C}$ for $10 \mathrm{~h}$ after washing by solvent). Liquid products are withdrawn periodically and analysed by gas chromatographically (Hewlett-Packard 5980/2 with flame ionisation detector and capillary column $(25 \mathrm{~m} / 0.32 \mathrm{~mm}$ i.d. HP-FFAP $))$. Temperature-programmed analysis (a temperature increase rate of $2{ }^{\circ} \mathrm{C} / \mathrm{min}$ from 60 to $130^{\circ} \mathrm{C}$ and onwards with a rate of $3{ }^{\circ} \mathrm{C} / \mathrm{min}$ up to $\left.215^{\circ} \mathrm{C}\right)$ and a nitrogen flow $(1 \mathrm{ml} / \mathrm{min})$ are applied for products separation.

\section{Results and discussion}

Important trends are revealed by a comparison of samples adsorption isotherms (Fig. 1).

Table 1

Samples characteristics

\begin{tabular}{|c|c|c|c|c|c|}
\hline & $\operatorname{Beta}(20)$ & $\operatorname{Beta}(55)^{\mathrm{a}}$ & $\operatorname{Beta}(66)$ & $m \operatorname{Beta}(66-48)^{\mathrm{a}}$ & $m \operatorname{Beta}(66-113)^{\mathrm{a}}$ \\
\hline$A_{\mathrm{BET}}\left(\mathrm{m}^{2} / \mathrm{g}\right)$ & 400.7 & 612.9 & 229.9 & 758.9 & 676.0 \\
\hline$V_{\max }(\mathrm{ml} / \mathrm{g})$ at $P / P_{0}=0.98$ & 167.26 & 626.01 & 617.56 & 613.43 & 509.42 \\
\hline Limiting micropore volume, $W_{0}\left(\mathrm{~cm}^{3} / \mathrm{g}\right)$ (Dubinin-Astakhov) & 123.4 & 184.8 & 71.5 & 238.3 & 214.1 \\
\hline$n$ & 3.79 & 1.94 & 1.41 & 1.40 & 1.28 \\
\hline$V_{\text {micro }}(t$-plot $)\left(\mathrm{cm}^{3} / \mathrm{g}\right)$ & 0.172 & 0.182 & 0.018 & 0.008 & 0.005 \\
\hline$A_{\text {ext }}(t$-plot $)\left(\mathrm{m}^{2} / \mathrm{g}\right)$ (meso- and macropores) & 43.3 & 227.7 & 182.7 & 985.5 & 768.1 \\
\hline$A_{\text {micro }}(t$-plot $)\left(\mathrm{m}^{2} / \mathrm{g}\right)^{\mathrm{b}}$ & 357.4 & 385.3 & 47.2 & - & - \\
\hline Average half-width of pores $(\mathrm{nm})$ & 0.501 & 0.672 & 1.08 & 1.066 & 1.062 \\
\hline$A_{\text {Langmuir }}\left(\mathrm{m}^{2} / \mathrm{g}\right)$ & 553.7 & 837.3 & 319.7 & 1052.6 & 942.4 \\
\hline Acid sites (mmol/g) & 1.00 & 0.86 & 0.56 & 0.46 & 0.53 \\
\hline $\operatorname{FTIR}(L / B)^{\mathrm{c}}$ & 0.40 & 1.15 & 1.35 & 0.016 & 0.17 \\
\hline \multicolumn{6}{|l|}{ Percent of volume of pores } \\
\hline $50-100 \AA^{3}$ & 17.09 & 22.34 & 39.98 & 9.39 & 12.74 \\
\hline $100-200 \AA^{3}$ & 24.57 & 51.63 & 48.72 & 13.30 & 14.11 \\
\hline $200-300 \AA^{3}$ & 37.16 & 7.19 & 8.59 & 8.48 & 8.48 \\
\hline
\end{tabular}

${ }^{a}$ Calcined at $823 \mathrm{~K}$ in an electric furnace before transformation in hydrogen form.

${ }^{\mathrm{b}} A_{\text {micro }}=A_{\mathrm{BET}}-A_{t \text {-plot. }}$

${ }^{c} L$ is the integral intensity of the band at $1455 \mathrm{~cm}^{-1}$ and $B$ is the integral intensity of the band at $1540 \mathrm{~cm}^{-1}$ in the IR spectrum of adsorbed pyridine after evacuation at $573 \mathrm{~K}$. 
Table 2

$\alpha$-Pinene conversion $\left(X_{\infty}\right)$ and the percentage of compounds in the reaction mixture, after $3 \mathrm{~h}$ of reaction

\begin{tabular}{lrrllllrrr}
\hline Catalysts & \multicolumn{1}{c}{$X_{\infty}$} & \multicolumn{1}{c}{1} & 2 & 3 & 4 & 5 & 6 & UP \\
\hline Beta(20) & 6.56 & 3.08 & - & 0.54 & 2.43 & - & 0.44 & 0.45 & - \\
Beta(55) & 99.24 & 27.58 & 7.64 & 4.20 & - & 13.37 & 5.69 & 2.60 & 31.71 \\
Beta(66) & 1.70 & 0.92 & 0.23 & - & - & - & - & - \\
$m$ Beta(66-48) & 99.32 & 26.20 & 5.83 & 5.12 & 4.82 & 18.58 & 11.40 & 3.15 \\
$m$ Beta(66-113) & 99.37 & 25.93 & 6.16 & 5.09 & 2.52 & 20.31 & 9.99 & 3.30 & 16.64 \\
\hline
\end{tabular}

$1=$ camphene, $2=$ tricyclene, $3=$ fenchenes, $4=$ limonene, $5=$ terpinenes, $6=$ terpinolenes.

The isotherm of Beta(20) is of type I, according to IUPAC classification, typical for microporous adsorbents. The isotherm of Beta(55), synthesised in hydrothermal conditions as Beta(20) but using another method of template removal, differs significantly. It is alike with the isotherm of Beta(66), obtained by a steam-assisted crystallisation method, and suggests the presence of textural mesoporosity [32]. The isotherms of $m$ Beta(66-48) and $m$ Beta(66-113) samples, both synthesised by mesostructuring of zeolite Beta seeds [30], are of type IV that reflects structural mesoporosity [33]. The abrupt step in the $P / P_{0}=0.40-0.55$ region indicates the existence of mesopores. It could be concluded that by using different methods of synthesis or template removal, samples with bimodal pores could be obtained. Having in mind that Beta zeolite structure has a high density of stacking defects, the formation of the second porosity most probably occurs by aluminium atoms removal at or near those stacking defects.

Significant differences in samples surface area and micropore volume are disclosed as well (Table 1).

The highest surface areas are determined for samples possessing structural mesoporosity - $m \operatorname{Beta}(66-48)$ and $m$ Beta(66-113). Nearly the same surface area is found for sample Beta(55) that is characterised by microporosity and secondary textural mesoporosity. Most probably, the strong dealumination during the template removal is the reason for the formed mesopores. As it is seen from Table 1, about $52 \%$ of the calculated pores volume lay in the range of $100-200 \AA$,

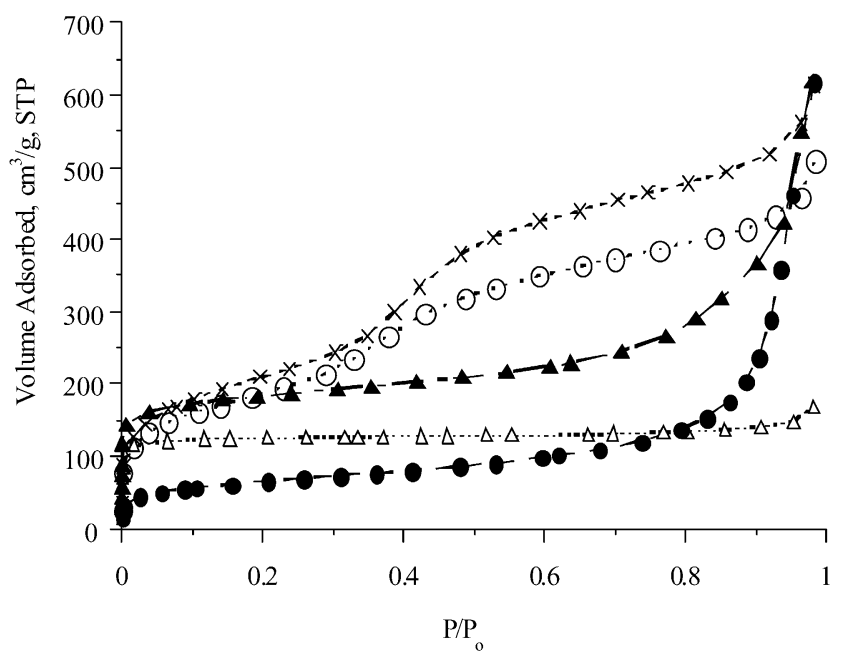

Fig. 1. Nitrogen adsorption isotherm of: $\operatorname{Beta}(20)(\triangle)$, $\operatorname{Beta}(55)(\boldsymbol{\Delta})$, $\operatorname{Beta}(66)(\bullet), m \operatorname{Beta}(66-48)(\times), m \operatorname{Beta}(66-113)(\bigcirc)$. a factor important for the catalytic transformation of large molecules. Sample Beta(20) is a typical microporous material characterised with BET surface area of $400 \mathrm{~m}^{2} / \mathrm{g}$. Sample Beta(66), prepared by steam-assisted method, reveals the lowest surface area $\left(230 \mathrm{~m}^{2} / \mathrm{g}\right)$. The calculated continuous decrease of the $n$ value from 3.79 to 1.28 for the different samples is apparent for the heterogeneity in their pore size distribution. So, the method of synthesis could serve as an instrument for the formation of pores with certain size.

The composition of the reaction mixtures in the presence of the investigated catalysts is given in Table 2. Products with higher retention times than terpinolene are noted as "HRTP" (high retention time products) and those with retention times in the range between $\alpha$-pinene and terpinolene as "UP" (unidentified products). The kinetic size of $\alpha$-pinene molecule $\left(144.8 \AA^{3}\right)$ is the smallest in comparison with the one of the reaction products as iso-terpinolene, limonene and $\alpha$-terpinene (146.9-147.2, 147.2-147.5, $145.5 \AA^{3}$, respectively) [34].

As it is seen, sample Beta(20) is practically not active for the isomerisation of $\alpha$-pinene, despite its high total acidity. Most probably this is due to the fact that its acidic centres are not accessible for the $\alpha$-pinene molecule. Beta(66) displays also low activity despite its higher total acidity and a high percent of volume of pores in the range of 100-300 . In a previous study [5], it was shown that its intrinsic characteristics significantly differ from the ones of the other samples, because of the different method of synthesis and template removal. As it is seen from Table 1, this sample

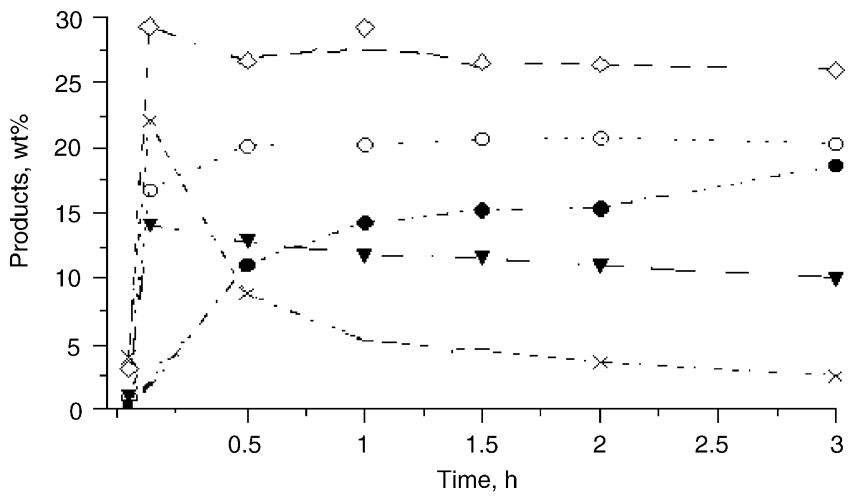

Fig. 2. Product distribution in $\alpha$-pinene isomerisation over $m \operatorname{Beta}(66-113)$ at $100^{\circ} \mathrm{C}$ : camphene $(\diamond)$, terpinenes $(\bigcirc)$, $\operatorname{HRTP}(\bullet)$, terpinolenes $(\boldsymbol{\nabla})$ and limonene $(x)$. 


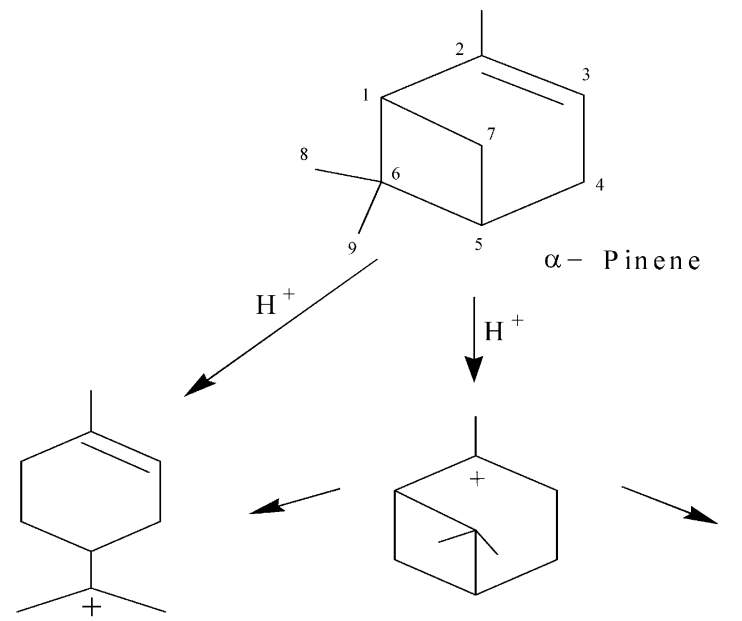

$p$-menthen ylcarbonium ion<smiles>C[InH]C</smiles>

$m$ B eta (66-113)<smiles>C=C(C)C1CC=C(C)CC1</smiles>

limonene<smiles>CC1=CCC(=C(C)C(C)(F)F)CC1</smiles>

terpinolene pinylcarbonium ion

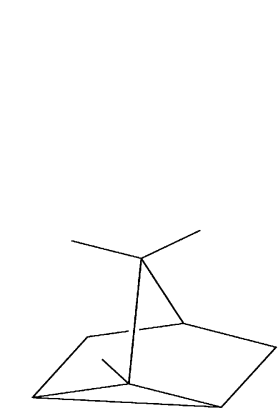

Tricyclene

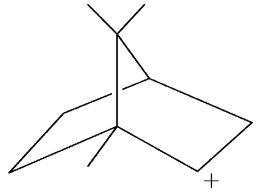

isobornylcarbonium ion

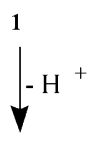

B eta (55)

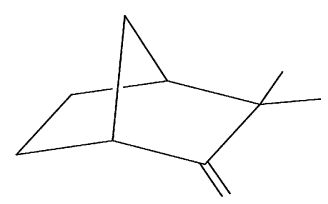

Camphene

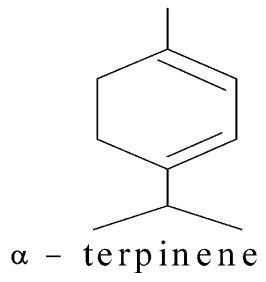

Scheme 1.

possesses the highest ratio of L/B acid centres as well. Thus, it is verified that the Brönsted acid sites are the one that are responsible for the isomerisation of $\alpha$-pinene but not the Lewis centres. An almost complete conversion of $\alpha$-pinene is reached over Beta(55) and $m$ Beta samples in an about half an hour from the reaction initialisation. The typical kinetic curves for $m \operatorname{Beta}(66-113)$ sample are presented in Fig. 2. The amount of camphene remains almost unchanged with the time. When $\alpha$-pinene is totally consumed, the camphene has almost equilibrium concentration, whereas secondary reactions with limonene proceed.

The isomerisation of $\alpha$-pinene over samples with secondary pore network likely occurs by the known mechanism postulated in many works. In the first step $\alpha$-pinene rapidly isomerises to $p$-menthenylcarbonium ion and pinylcarbonium ion, which is formed in an irreversible reaction (Scheme 1).

It could be assumed that the opening of the four-member ring is not sterically hindered in the presence of samples with mesopores. Next, a specific catalysts bearing is considered to- wards the conformation of $p$-menthenyl-cation, which could be influenced by the neighbouring acidic sites as well. Such a probability provokes opportunities for the more intense destabilisation of the intermediate for limonene production and

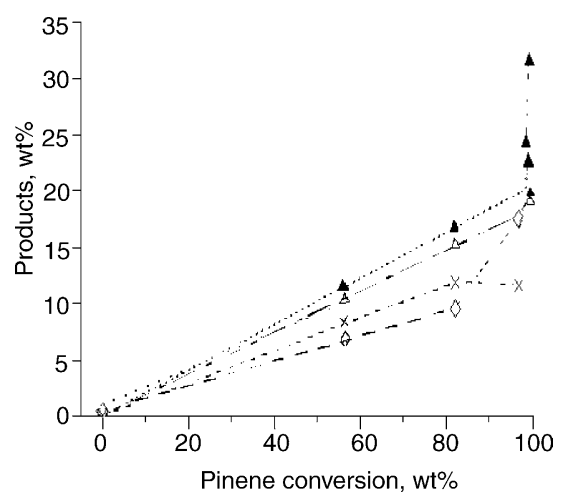

Fig. 3. Terpinenes and HRTP concentrations as function of $\alpha$-pinene conversion over: $\operatorname{Beta}(55)$-terpinenes $(\triangle)$, HRTP $(\Delta)$ and $m \operatorname{Beta}(66-$ 113)-terpinenes $(\diamond)$, HRTP $(\times)$. 


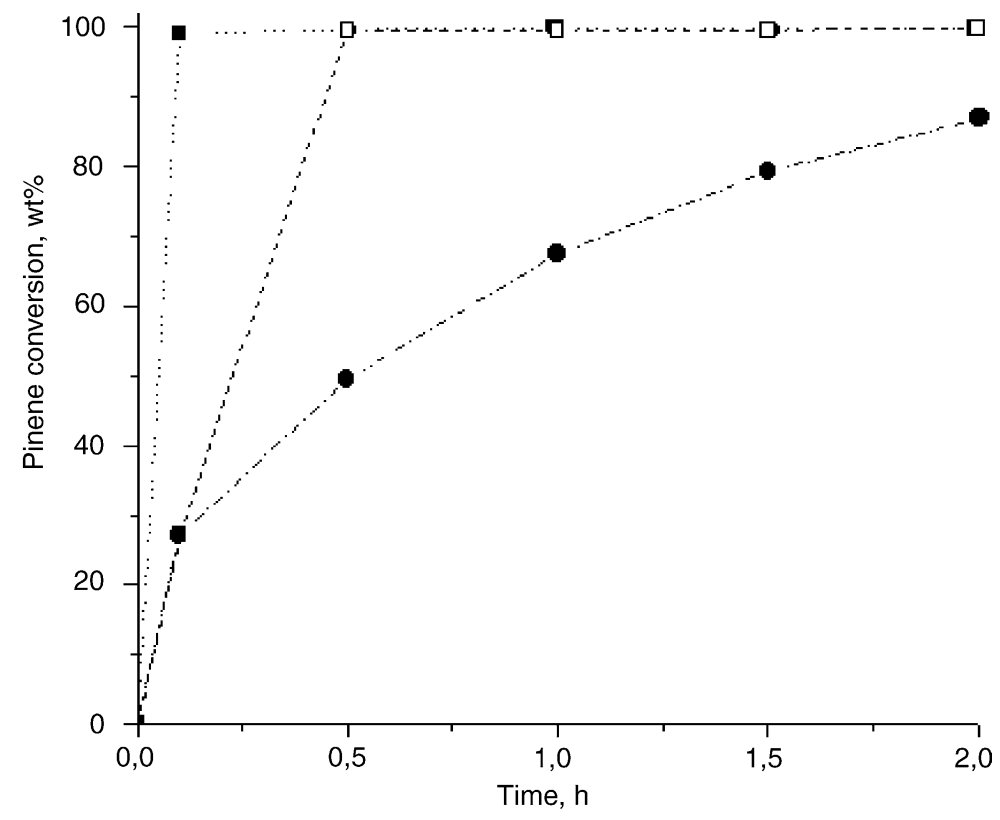

Fig. 4. $\alpha$-Pinene conversion vs. time on: fresh catalyst

), used catalyst ( ) and regenerated catalyst ( $\square)$.

therefore for its increased reactivity and conversion to other isomers.

Fig. 3 shows terpinenes and HRTP as a function of $\alpha$ pinene conversion. Similar results have been reported in literature [35].

As it is seen from Fig. 3, the products percents increase more over Beta(55) than over $m \operatorname{Beta}(66-48)$ sample. The HTRP products are produced by the disproportionation of terpinenes and terpinolenes. The formation of the spacious intermediate is favoured by the existence of pores with radius in the range of 100-200 $\AA$. The latter is about $52 \%$ of the total pore volume for $\operatorname{Beta}(55)$, while for $m$ Beta samples it is about $13-14 \%$ of total pore volume.

The effect of catalyst reuse on $\alpha$-pinene conversion is presented in Fig. 4 for Beta(55) sample, as the same effect is achieved for the other samples too.

As it is seen from Fig. 4, a complete conversion of $\alpha$ pinene $(99.6 \%)$ is obtained in the experiment with the fresh catalyst after about $30 \mathrm{~min}$. In the presence of reused catalyst, the conversion of $\alpha$-pinene increases for about $2 \mathrm{~h}$ up to $86.8 \%$. So, catalysts regeneration by solvent washing is insufficient to remove entirely the sorbed species. If the catalyst is calcined at $550{ }^{\circ} \mathrm{C}$, an identical activity for $\alpha$-pinene conversion with one of the fresh sample is detected. It is apparent that the acid sites strength of Beta(55) differs, most probably because of sites different localisation in the micro- or mesopores and environment. The products composition in the reaction mixture is the same in all experiments. So, it could be stated that the preferred camphene formation in the presence of $\operatorname{Beta}(55)$ is a result of an appropriate combination of samples textural and acidic properties.

\section{Conclusion}

The isomerisation of $\alpha$-pinene has been studied over Beta zeolites synthesised by different methods. The main products are camphene, terpinenes, terpinolenes and heavy products. It was confirmed that the isomerisation is an acid-catalysed reaction so that an active catalysts are the one with high enough number of Brönsted acid sites and strength. The most active catalysts are Beta(55) zeolite and the mesoporous samples $m$ Beta(66-48) and $m \operatorname{Beta}(66-113)$ because of the appropriate balance between its acidity and the developed mesopores system. The microporous samples Beta(20) and Beta(66) show low activity although they possess good total acidity.

\section{Acknowledgements}

Funding for this work from Turkish Scientific Research Council through Grant MISAG-Bulgaria 1 and from Bulgarian Academy of Sciences is gratefully acknowledged. The authors thank Burcu Atalay and Hilal Güleç for the experiments of $\alpha$-pinene isomerisation.

\section{References}

[1] H. Ajot, J.F. Joly, J. Lynch, F. Raatz, P. Caullet, in: F. RodriguezReinoso (Ed.), Characterization of Porous Solids II, Elsevier, Amsterdam, 1991, p. 583.

[2] J.A. van Bokhoven, D.C. Koningsberger, P.J. Kunkeler, H. van Bekkum, A.P.M. Kentgens, J. Am. Chem. Soc. 122 (2000) 12842.

[3] A.E.W. Beers, J.A. van Bokhoven, K.M. de Lathouder, F. Kapteijn, J.A. Moulijn, J. Catal. 218 (2003) 239. 
[4] S. Bernasconi, J.A. van Bokhoven, F. Krumeich, G.D. Pirngruber, R. Prins, Microp. Mesop. Mater. 66 (2003) 21.

[5] R. Dimitrova, G. Gündüz, L. Dimitrov, T. Tsoncheva, S. Yilmaz, E.A. Urquieta-Gonzalez, J. Mol. Catal. A: Chem. 214 (2004) 265.

[6] J. Lynch, F. Raatz, C. Delalande, in: K.K. Unger (Ed.), Characterization of Porous Solids, Elsevier, Amsterdam, 1988, p. 547.

[7] A.H. Janssen, A.J. Koster, K.P. de Jong, Angew. Chem., Int. Ed. Engl. 40 (2001) 1102.

[8] M.M. Olken, J.M. Graces, in: R. von Ballmoos, J.B. Higgins, M.M.J. Treacy (Eds.), Proceedings of the Ninth International Zeolite Conference, 1992, p. 559.

[9] L. Bertea, H.W. Kouwenhoven, R. Prins, Appl. Catal. A: Gen. 129 (1995) 229.

[10] F. Himidi, A. Bengueddach, F. Renzio, F. Fajula, Catal. Lett. 87 (2003) 149.

[11] M. Tromp, J.A. van Bokhoven, M.T.G. Oostenbrink, J.H. Bitter, K.P. de Jong, D.C. Koningsberger, J. Catal. 190 (2000) 209.

[12] S. Lingling, L. Lin, Z. Tiangin, W. Hongxia, L. Yonggang, Ah. Wenjie, X. Yide, B. Xinhe, Catal. Lett. 91 (2003) 155.

[13] Zhang, Q. C., Z. Liu, K. Xu, L. Wan, Microp. Mesop. Mater. 62 (2003) 157.

[14] C. Zhang, Q. Liu, Z. Xu, K. Wan, Microp. Mesop. Mater. 62 (2003) 157.

[15] C.M. Lopez, F.J. Machado, K. Rodriguez, B. Mendez, M. Hasegawa, S. Pekarar, Appl. Catal. A: Gen. 173 (1998) 75.

[16] T. Yamamota, T. Tanaka, T. Funabilei, S. Yoshida, J. Phys. Chem. B 102 (1998) 5830.

[17] T.S. Sorensen, Acc. Chem. Res. 9 (1976) 257.

[18] N. Besgun, F. Özkan, G. Gündüz, Appl. Catal. A: Gen. 224 (2002) 285.
[19] Kr.Y. Mukesh, D.Ch. Chintansinh, R.V. Jasra, J. Mol. Catal. A: Chem. 216 (2004) 51.

[20] S. Findik, G. Gündüz, JAOCS 74 (9) (1997) 1145.

[21] A. Allahverdiev, G. Gündüz, D. Yu Murzin, Ind. Eng. Chem. Res. 37 (1998) 2373.

[22] F. Özkan, G. Gündüz, O. Akpolat, N. Besgün, D. Yu Murzin, Chem. Eng. J. 91 (2003) 257.

[23] C.M. Lopez, F.J. Machado, K. Rodriguez, D. Arias, B. Mendez, M. Hasegawa, Catal. Lett. 62 (1999) 221.

[24] C.M. Lopez, F.J. Machado, K. Rodriguez, B. Mendez, M. Hasegawa, S. Pekarar, App. Catal. A: Gen. 173 (1998) 75.

[25] A. Severino, A. Esculcas, J. Rocha, J. Vital, L.S. Lobo, Appl. Catal. A: Gen. 142 (1996) 255.

[26] J.C. Vander Waal, H. Van Bekkum, J.M. Vital, J. Mol. Catal. A: Chem. 105 (1996) 185.

[27] C.M. Lopez, K. Rodriguez, B. Mendez, A. Montes, F.J. Machado, Appl. Catal. A: Gen. 197 (1) (2000) 131.

[28] C.M. Lopez, K. Rodriguez, B. Mendez, A. Montes, F.J. Machado, Appl. Catal. A: Gen. 197 (1) (2000) 131.

[29] M. Matsuka, T. Osaki, M. Ogura, E. Kikuchi, Microp. Mesop. Mater. 56 (2002) 1.

[30] J. Gregg, K.J.W. Sing, Adsorption, in: Surface Area and Porosity, Academic Press, New York, 1982, p. 197.

[31] M.M. Dubinin, V.A. Astakhov, Adv. Chem. Ser. 102 (1970) 69.

[32] L. Liu, W. Zhang, T. Pinnavaia, Angew. Chem. 113 (2001) 295.

[33] A.D. Stefanis, G. Perez, O. Ursini, A.A.G. Tomlinson, Appl. Catal. A: Gen. 132 (1995) 353.

[34] T. Yamamota, T. Tanaka, T. Funabilei, S. Yoshida, J. Phys. Chem. B 102 (1998) 5830.

[35] K. Yoo, E. Burckle, P. Smirniotis, Catal. Lett. 74 (2001) 85. 